Abstract G492 Table 1 Associations between early adolescent health and low educational attainment in late adolescence and NEET status in early

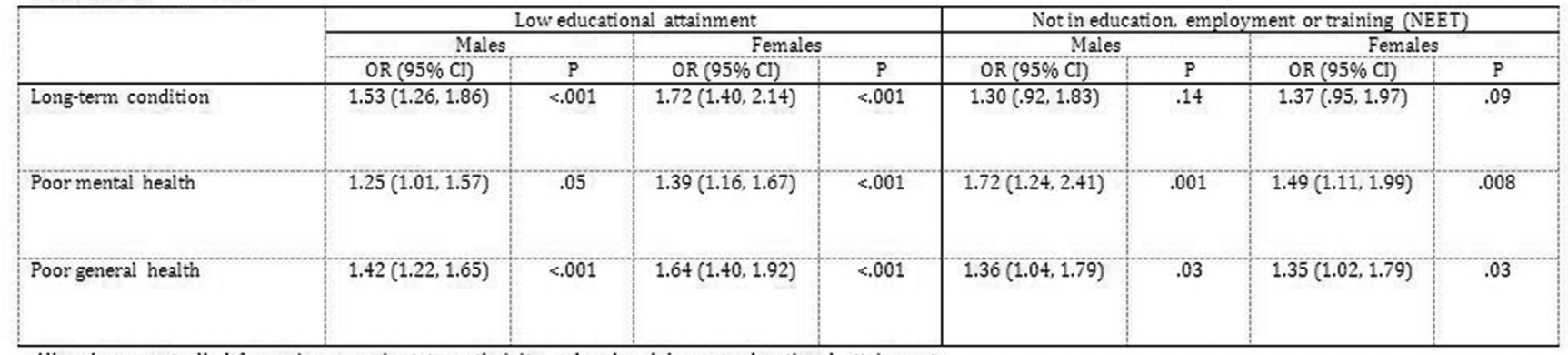

All analyses controlled for socioeconomic status, ethnicity and early adolescent educational attainment.

\section{G493 HOW CAN HEALTH SERVICES EFFECTIVELY IMPROVE THE MENTAL HEALTH OF YOUNG PEOPLE LEAVING PUBLIC CARE? THE LYNC STUDY}

${ }^{1} \mathrm{SJ}$ Butterworth, ${ }^{2} \mathrm{Z}$ Islam, ${ }^{3} \mathrm{P}$ Vostanis, ${ }^{4} \mathrm{E}$ Munro, ${ }^{2} \mathrm{M}$ Paul, ${ }^{2} \mathrm{M}$ Birchwood, ${ }^{2} \mathrm{~S}$ Singh, ${ }^{1} \mathrm{~A}$ Khan, ${ }^{2} \mathrm{D}$ Simkiss. ${ }^{1}$ Research and Innovation, Birmingham and Solihull Mental Health NHS Foundation Trust, Birmingham, UK; ${ }^{2}$ Warwick Medical School, Warwick University, Warwick, UK; ${ }^{3}$ Greenwood Institute of Child Health, University of Leicester, Leicester, UK; ${ }^{4}$ Department of Childhood, Families and Health, Thomas Coram Research Unit, London, UK

\subsection{6/archdischild-2015-308599.446}

Aim To explore the mental health needs and service use of young people transitioning out of local authority care.

Methods A mixed-method study in one local authority. Qualitative methods included a thematic analysis of interviews with 12 care leavers with an identified mental health need and 12 relevant staff members from across the agencies involved with young people. Quantitative methods for analysing transition included screening social care and health service notes from age 15 of 40 care leavers aged 18-22 years. Analysis documented the completeness of pathway planning (adherence to national guidance), identified mental health needs (diagnoses, service involvement) and the effectiveness of CAMHS to AMHS transition (information continuity, joint working, transition planning and continuity of care).

Results Qualitative analysis of care leaver interviews generated four superordinate themes: overarching attitudes towards the care journey, experience of social care, experience of mental health services and recommendations. Qualitative analysis of staff interviews produces six superordinate themes: young people's lives, the transition process, system failure, professionals' understanding of mental illness, inter-agency working, capacity and limited service. Initial quantitative analysis showed that during transition young people were very mobile, expressed high mental health needs and accessed multiple mental health services with a high rate of crisis pathways. Data on the quality of transition will be analysed in December 2014 and will be available for presentation at the ASM.

Conclusion Care leavers with mental health problems face many transitions and felt abandoned with a poor experience of services during this time. Staff said transitions were often poorly delivered with care leavers ill-equipped to manage. They said that inter-agency working was weak, without a shared protocol or information sharing or a collaborative approach to care. Recommendations for improving transition include joint commissioning across the transition period, continuity between child and adult services, staff training, care-leavers active involvement, identification and evaluation of best practice models. Further research is needed to develop and rigorously evaluate models of transitional care that promote mental health and wellbeing.

\section{G494 EXTREME CHILDHOOD OBESITY: AN EXTERNAL SIGN OF PSYCHOSOCIAL AND EMOTIONAL PROBLEMS}

V Impey, H Tuffin, A Lorek, C Dempster. Lambeth Healthy Weight Project, South London and Maudsley, Guy's and St Thomas' NHS Trusts, London, UK

\subsection{6/archdischild-2015-308599.447}

Methods Evaluation of referrals of families referred to Tier 3 obesity service for children 4-12 years with BMI $>98^{\text {th }}$ centile (or $91^{\text {st }}$ centile with complexity), previously unengaged. Project ethos based in principles of systemic family psychotherapy, approached the problem following NICE 2013 guideline Childhood Obesity. Family therapist, dietician, activities specialist and paediatrician, offered a comprehensive outreach approach including home visits. Initial assessment explored causes and complications of obesity including Strengths and Difficulties questionnaire SDQ and assessment of child's mental health. Goals were set with families including parenting/family therapy. Families were seen fortnightly for 3 months, assessed 3 monthly, up to 1 year.

Results 144 referred: School Nursing Team (71); Community Paediatricians (37); Others (36). 120/144 (83\%) met criteria for clinic. Of these $72 / 120(60 \%)$ accepted first appointment (no response from 20/120(16\%), declined by 28/120(23\%)) Ethnicity of children: White 19\%, Black British/African/Caribbean 60\%, Other 20\%. English as additional language 33/72(46\%), 9 requiring interpreter. All were $>98<$ sup style="font-family: Arial, sans-serif;" > th centile BMI. Almost all children engaged stabilised BMI z scores at 3 months. (20/23 (87\%).

Frequent psychosocial factors identified includied lone parent 27/72(38\%); siblings/parent physically disabled;12/72(17\%); no parent employed 17/72(24\%), current/previous social services 12/72(17\%), domestic violence 9/72(13\%), parental mental illhealth:8/72(11\%). Neurodevelopmental disorders included autism, Down's syndrome, ADHD, Cerebral palsy, learning disability and medical problems, plus significant behavioural difficulties.

Initial SDQ indicated substantial risk of clinical significance 19/72(26\%). Two children were suicidal and self harm concerns in four. Referrals were made to social services for CIN or CP concerns (12/72) (17\%).

Conclusion Extreme obesity in children is systemic and multifactorial, often associated with concerning psychosocial problems in families. Paediatricians who care for children who are 
extremely obese should enquire about mental health, parenting, development and psychosocial factors, and make appropriate referrals. Childhood obesity often indicates family distress and unmet need including important child mental health difficulties.

\section{G495 INNOVATIVE TREATMENTS FOR CHILDREN: A SINGLE CENTRE REVIEW OF CLINICAL ETHICS COMMITTEE DISCUSSIONS}

HL Turnham, T Radcliffe, J Brierley. Paediatric Intensive Care, Great Ormond Street Hospital, London, UK

\subsection{6/archdischild-2015-308599.448}

Aims Lord Saatchi's proposed Medical Innovation Bill (MIB) has received widespread media and public interest. The Bill aims to encourage doctors to try novel treatments for those reaching the limit of standard therapy, promising protection from sanctions e.g. prosecution.

Innovative therapies (IT) are a relatively common undertaking in the rare and occasionally unique diseases encountered in children's hospitals, children are not discussed in the proposed Bill.

Brierley and Larcher proposed an ethical framework to review IT in children and we describe cases reviewed by our Clinical Ethics Committee (CEC) since introducing this approach.

Methods Tertiary paediatric hospital CEC transcripts regarding IT proposals 2011-14 reviewed.

Discussion In four years the CEC reviewed 13 IT cases, 6 were urgent and reviewed by rapid response committee. Proposals were presented by 11 different paediatric specialities - 9 single patient specific, 4 relevant to multiple patients.

The CEC consisted of at least one medical, one lay member and a member with a higher degree in medical ethics. A legal adviser attended 7 meetings and a member of the hospital spiritual team 8. Minimum of 5 CEC members at review (range 5-13). Families attended all single patient reviews.

In all cases in line with the framework medical teams justified the scientific basis for treatment (1) and provided second opinions of external specialists in the field (2). The clear informed consent to the specific proposal by the child and/or those with parental responsibility (3) were obtained, including full knowledge of alternative possibilities e.g. palliative care.(4) The entire local, and where relevant external referring, teams agreed this treatment was an appropriate course.(5) Wider issues such as burdens of treatment for the child and family as a whole (6) together with funding implications for treatment (7) and other resources e.g. PICU were also discussed. An explicit guarantee to disseminate the result of IT whatever the outcome from the team was made.

Conclusion Our CEC offers medical teams the opportunity to have innovative therapies reviewed by a multidisciplinary group using a published framework. Innovation is already happening and we are not persuaded the MIB is necessary, or protection from prosecution sensible.

\section{G496 CARING FOR BODY AND SOUL - NAVIGATING RELIGIOUS OBJECTIONS BY MUSLIM PARENTS}

${ }^{1}$ A Sabir, ${ }^{2}$ A Yusuf, ${ }^{1}$ BJ Muhammed. 'Paediatric and Neonatal Unit, Walsall Manor Hospital, Walsall, UK, ${ }^{2}$ Psychiatry, Penn Hospital, Wolverhampton, UK

10.1136/archdischild-2015-308599.449
Aim We present a 6 day old boy who suffered femoral arterial thrombosis. Parents are Muslim and disagree with the use of Heparin, as it contains pork-derived gelatine. We explore medico-religious conflict between Muslim parents and health-care professionals and how to navigate them.

Methods Male, born 38+2 weeks, NVD, $4.63 \mathrm{~kg}$. Antenatal scans and serology were normal, despite maternal gestational DM (Insulin controlled). He was diagnosed with pulmonary hypertension and HOCM requiring mechanical ventilation for 5 days. Umbillical artery catheterisation inserted on D1, removed on D6 leading to femoral artery thrombosis.

Whilst awaiting emergency transfer to a surgical centre, Heparin was required but parents objected on religious grounds. Results In the absence of suitable alternatives, we explored parent's ideas, concerns and expectations. Explaining the gravity of the situation, they still objected. Measures such as contralateral limb warming, volume expansion and GTN patches were insufficient. Seeking court approval to override the objection was under exploration and if the condition deteriorated Heparin was to be used without parental consent based on 'best interest'. Parents agreed to Heparin before this occurred. Surgery was averted and the clot resolved with Heparin infusion alone.

Conclusion Muslims come from many theological and legal backgrounds. Some view that unlawful material for consumption is unlawful for use in medicine, such as pork-derived gelatine. Many medicines contain such gelatine, e.g. Heparin, HepSaline flushes and Duoderm. When conflicts arise, the following can help as per the Hanafi legal school;

- Explore parents concerns, explain the situation sensitively. Involve chaplains and Muslim scholars.

- Consider an alternative if available, e.g. Mepitel for Duoderm.

- If no alternative is available or sufficiently effective then one can use the product, as long as it is needed, known to be effective (based on atleast high likelihood) and that this has been established by a qualified doctor who appreciates the ethical framework of Islamic law.

- Provide information as many Muslims lack knowledge of the facility present in Islamic law, e.g. a religious edict (fatwa) such as that written by Al-Azhar University for use of Duoderm or articles from reliable Islamic authorities; seekersguidance.org.

It is important for clergy and professionals to learn about Islamic medico-legal ethics.

\section{G497(P) HUMAN PAPILLOMA VIRUS VACCINATION COVERAGE RATES IN 'LOOKED AFTER' YOUNG WOMEN - ANOTHER MARKER OF HEALTH DISADVANTAGE?}

${ }^{1} \mathrm{D}$ Beasley, ${ }^{1} \mathrm{JA}$ Harris, ${ }^{2} \mathrm{H}$ Hutchings, 'PM Barnes. 'Department of Community Child Health, ABM University Health Board, Swansea, UK; ${ }^{2}$ Centre for Health Information Research and Evaluation (CHIRAL), College of Medicine, Swansea University, Swansea, UK

\subsection{6/archdischild-2015-308599.450}

Aims Vaccination of young women against human papilloma virus (HPV) has important health benefits, not least in reducing lifetime cervical cancer risk. Young women who are 'looked after' are a vulnerable group, known to face disadvantage in several areas, including in relation to their health. Are we able to achieve HPV coverage rates in this group comparable to the general population in order to safeguard their future health? We set out to study this in our own Health Board area. 